\title{
Gender-based Multilevel Analysis of Influential Factors for Suicide Attempts among At-risk Non-referred Adolescents in Korea
}

\author{
Yumi Lee ${ }^{1}$, Dayoung Lee ${ }^{1}$, Hyun Ju Hong ${ }^{1,2}$ \\ ${ }^{1}$ Hallym University Suicide and School Mental Health Institute, Hallym University Sacred Heart Hospital, ${ }^{2}$ Department of Psychiatry, Hallym \\ University Sacred Heart Hospital, Anyang, Korea
}

\begin{abstract}
Objective: Effective suicide prevention for at-risk adolescents requires increased access to medical treatment. Investigating the unique characteristics of suicide in this vulnerable at-risk non-referred sample can contribute to establishing effective suicide prevention policies. This study aimed to (a) examine at-risk non-referred adolescents' suicide attempt rate, (b) investigate influential multilevel factors in predicting these adolescents' suicide attempts, and (c) compare the results of (a) and (b) by gender.

Methods: A total of 401 samples (216 boys and 185 girls) were recruited through a school-based mental health project for at-risk adolescents. Multivariate hierarchical logistic regression analyses were performed at the individual-, contextual-, and protective levels to evaluate three multilevel models as well as to investigate predictabilities for the overall group and by gender.

Results: The suicide attempt rate of the overall sample was 29.4\% (boys: $18.1 \%$, girls: 42.7\%), which was significantly higher than that of community samples. For boys, individual-level predictors (depression and conduct problems) had the most significant contribution in predicting suicide attempts. In contrast, for girls, protective-level predictors (family satisfaction) contributed the most to the prediction of suicide attempts, followed by contextual-level predictors (academic grades).

Conclusion: This study is an important step in understanding the unique characteristics of at-risk non-referred adolescents who have not yet been considered in mental health policies. Improving medical accessibility will be the first step in establishing effective suicide prevention policies for these vulnerable samples.
\end{abstract}

KEY WORDS: Suicide, attempted; Mental health; School; Vulnerable; Students.

\section{INTRODUCTION}

Suicide attempts are intentional self-harming behaviors, that are a significant factor affecting committed suicides [1-4]. Overall, 30\% of adolescents who attempted suicide had again attempted it within a year, and $5 \%$ had died by suicide after nine years [5-7]. According to national data in Korea, the suicide attempt rate of adolescents (aged 13-18 years) was $2.6 \%$ in 2017 [8]. This rate differs according to gender and samples. Girls' suicide at-

Received: April 16, 2019/Revised: June 20, 2019

Accepted: June 24, 2019

Address for correspondence: Hyun Ju Hong

Hallym University Suicide and School Mental Health Institute,

Hallym University Sacred Heart Hospital, 22 Gwanpyeong-ro

170beon-gil, Dongan-gu, Anyang 14068, Korea

E-mail: honghj88@gmail.com

ORCID: https://orcid.org/0000-0002-6348-9996 tempts $(3.2 \%)$ were reported to be higher than those of boys (2.0\%) [8]. In addition, adolescent who had diagnosed with a depressive disorder (i.e., clinically depressed samples) reported a significantly higher rate of suicide attempts (47.2\%) [9] compared to community samples.

A systematic review of the literature indicated that adolescent suicides are caused by multidimensional factors, including individual and contextual factors [1,4,10-18]. Individual factors refer to personal characteristics that affect adolescents' suicidal behaviors, including gender $[1,10,19,20]$, mental disorders such as depression $[9,14,16]$, and attention-deficit/hyperactivity disorder (ADHD) [21-23], and psychological impairment (e.g., conduct and emotional problems) [18,24,25]. A significant gender difference was also found. Whereas depression, emotional symptoms, and peer problems are more common in girls $[9,10,26]$, ADHD, hyperactivity,

(ㄷ) This is an Open-Access article distributed under the terms of the Creative Commons Attribution Non-Commercial License (http://creativecommons.org/licenses/by-nc/4.0) which permits unrestricted non-commercial use, distribution, and reproduction in any medium, provided the original work is properly cited. 
and conduct problems are more common in boys $[22,23,27]$.

Contextual factors include school (e.g., academic grades) and family factors (e.g., economic status) $[18,28,29]$ as the representative environmental factors of adolescents' suicidal behaviors. School levels do not necessarily coincide with age, and each school level has a different educational administration system and curriculum, causing significant differences in the school environment. Thus, it is assumed that school level is an important contextual factor for adolescents. The highest suicide attempt rate for boys was in high school (10th grade), and that of girls was in middle school (8th grade) [30]. In addition, suicide attempt rates for both boys and girls were highest when academic grades were low $[30,31]$. Furthermore, family-related variables proved to have a significant impact on suicide attempts $[29,32]$. The suicide attempt rate was higher when the family structure was unstable [33], family economic status was low [34], and there was abuse in the family [35]. However, no gender-specific analysis has been conducted regarding family-related variables.

In addition to individual and contextual factors, overall quality of life (i.e., life satisfaction) has proven to be an influential protective factor to reduce adolescent suicide attempts $[29,35,36]$. Adolescents who attempted suicide reported a significantly lower level of life satisfaction compared with those who had no such attempt experience $[26,37]$. A gender difference was also found. Boys had higher life satisfaction than girls, and girls were more affected by their satisfaction in life compared to boys [38,39].

Due to limitations in collecting data from research subjects, to date, studies on suicide have targeted either community samples or clinical samples (e.g., psychiatric in-patients or emergency room patients) $[2,4,9,15,29,40]$, very few studies have been conducted with at-risk non-referred adolescents who have not visited or been unable to visit the hospital. In Korea, 2.6\% (boys: 2.0\%, girls: 3.2\%) of adolescents have attempted suicide in the last 12 months, and the rate of psychiatric treatment after suicide attempts was $17.9 \%$ (boys: $25.1 \%$, girls: 13.1\%) [41]. Effective suicide prevention for at-risk adolescents requires increased access to medical treatment; however, many at-risk adolescents do not receive professional psychiatric services due to various reasons (e.g., negative per- ceptions and/or financial difficulties). Investigating the unique characteristics of suicide in this vulnerable at-risk non-referred sample can contribute to establishing effective suicide prevention policies. Therefore, this study aimed to (a) examine at-risk non-referred adolescents' suicide attempt rate, (b) investigate influential multilevel factors in predicting these adolescents' suicide attempts, and (c) compare the results of (a) and (b) by gender (boys vs. girls).

\section{METHODS}

\section{Data}

Since 2012, the Ministry of Education of Korea (MEK) has conducted Mental Health Screening Tests among 1st and 4th grade elementary students, 1st grade middle school students, and 1st grade high school students. Approximately $99 \%$ of students receive this test, and about $5 \%$ are classified as high risk. Schools are required to encourage high-risk students to obtain services by referring to specialized mental health professionals [18]. However, $20-30 \%$ of high-risk students do not visit external professionals for various reasons, such as parents not acknowledging their child's problem/difficulties or environmental constraints. Since 2016, the MEK has implemented the Professional School Visits Project, which is an outreach program to support these adolescents. This project operates seven regional centers nationwide; each center employs several trained mental health professionals and a psychiatrist with at least ten years of clinical experience as its director. Upon request from a school, mental health professionals visit the school and conduct standardized interviews with students, parents, and teachers. After the interviews are completed, case conferences are held to establish management plans for each student through discussion with team members and the psychiatrist. Based on the case conference, students are provided with compensation for their psychiatric treatment expenses or a referral to the public welfare service system, and parents and teachers are provided with mental health education and counseling to help them understand and manage their child/student's problems.

In this study, data from 1,151 middle and high school students who received mental health services through the Professional School Visits Project in 2017 were first included. Then, 461 students who received medical ex- 
penses compensation were chosen as the at-risk non-referred adolescents. These students were chosen because the criteria for medical expenses compensation are students needing psychiatric care but who refuse psychiatric treatment due to socioeconomic reasons or negative perceptions of psychiatric treatment. Among them, 50 students were excluded due to missing data. As a result, a total of 401 students (216 boys and 185 girls) were finally included in this study. The age range was 13 to 18 years old (mean $[M]=14.96$, standard deviation $[S D]=1.56$ ).

\section{Measures}

The individual-level predictors were divided into three folds: gender (1 item), clinical diagnosis (2 items), and mental health status (4 items) as follows. First, gender was the sub-group of this study $(0=$ boy, $1=$ girl). Second, clinical diagnoses of depression and ADHD, the most common diagnoses associated with adolescents' suicidal behaviors, were selected $(0=$ without diagnosis, $1=$ with diagnosis). These diagnoses were confirmed by psychiatrists based on the criteria of the Diagnostic and Statistical Manual of Mental Disorders-5 (DSM-5) during the clinical evaluation stage. In this study, major depressive disorder, persistent depressive disorder, and unspecified depressive disorder of DSM-5 were classified as depression category. We excluded disruptive mood dysregulation disorder or bipolar disorder. Third, the self-reported Strengths and Difficulties Questionnaire (SDQ) was used for mental health status. The SDQ is a behavioral screening questionnaire developed by Goodman [42]. The SDQ consists of 25 items, including five sub-scales: prosocial behaviors, hyperactivity-inattentive, emotional symptoms, conduct problems, and peer problems. The peer problems of SDQ were classified as individual factors because the items constituting peer problems (e.g., "I am usually on my own, I generally play alone or keep to myself”) are similar to individual characteristics related to peer relationships. For this study, the validated Korean version of the self-reported SDQ [43] was adapted (four difficulties sub-scales: total of 20 items). The internal consistency of the Korean version of the self-reported SDQ was between 0.80 and 0.90 [43], and that of the current study was between 0.57 and 0.79 . For the conduct problems subscale, one item, "I usually do what I'm told," was excluded due to low reliability.

The contextual-level predictors were divided into two folds: school-related factors (2 items) and family-related factors (3 items). First, school-related factors included school level $(0=$ middle school, $1=$ high school $)$ and academic grades (from 1 = poor to 5 = excellent). Second, family-related factors included family structure $(0=$ nuclear, 1 = others), family economic status (public assistance recipients) $(0=$ no, $1=$ yes $)$, and abuse experience ( $0=$ no, 1 = yes $)$.

The protective-level predictors indicated their satisfaction in life. The Multidimensional Students' Life Satisfaction Scale (MSLSS) is a perceived life satisfaction questionnaire developed by Huebner [44]. The MSLSS consisted of 40 items, including five sub-scales: family, friends, school, living environment, and self-satisfaction. For this study, the validated Korean version of the MSLSS (K-MSLSS) [45] was used (three sub-scales: family, friends, and school; a total of 18 items). The internal consistency in the Korean study was between 0.62 and 0.88 [45], and that of the current study was between 0.90 and 0.93 .

Data for the outcome variable, suicide attempt status $(0=$ absent, 1 = present), were collected from clinical interviews with mental health professionals at the clinical evaluation stage, about experiences such as self-injury and suicide attempts within the last 12 months.

\section{Statistical Analysis}

SPSS 23.0 (IBM Co., Armonk, NY, USA) was used to analyze the data as follows. First, descriptive analyses were conducted to examine all predictors' characteristics at baseline, and group differences between the genders. Specifically, $t$ test and chi-square $\left(\chi^{2}\right)$ analysis were conducted to assess gender differences. Second, correlation analysis was conducted to identify multicollinearity between the 15 predictors. Third, univariate logistic regression analysis was performed to determine whether each variable predicted adolescents' suicide attempts. Then, multivariate hierarchical logistic regression analyses were performed (at the individual-, contextual-, and protective-levels) using 11 predictors to evaluate three multilevel models as well as to investigate predictive capabilities for the overall group and by gender. The predictors were entered in three separate blocks in the multilevel regression equation. First, seven individual-level predictors were entered in block 1 (at the first level). Second, two contextual factors (school level and academic grades) were entered in block 2 (at the second level). 
Finally, two protective factors (family and school satisfaction) were added in block 3 (at the third level) (statistical significance: $\left.{ }^{*} p<0.05,{ }^{* *} p<0.01,{ }^{* * *} p<0.001\right)$.

\section{RESULTS}

\section{Descriptive Analysis of Three-level Predictors}

The clinical characteristics of the overall sample are shown in Table 1. In total, data from 216 boys and 185 girls were analyzed, accounting for $53.9 \%$ and $46.1 \%$, respectively. Of 15 predictors, six predictors showed sig- nificant gender differences between boys and girls as follows. With regard to level 1, whereas girls (56.8\%) were diagnosed with depression more than boys (28.7\%), boys (30.1\%) were diagnosed with ADHD more than girls (8.6\%). Also, girls $(M=1.32, \mathrm{SD}=0.47)$ had significantly greater emotional symptoms than boys $(M=0.91, \mathrm{SD}=$ 0.57). In terms of level 2, middle school boys (aged $13-$ 15 years; 67.1\%) and high school girls (aged 16-18 years; $45.4 \%$ ) were referred to mental health professionals significantly more often than the opposite genders (middle school girls: $54.6 \%$, high school boys: $32.9 \%$ ).

Table 1. Descriptive analysis of three-level predictors and outcome variable for the overall sample and by gender

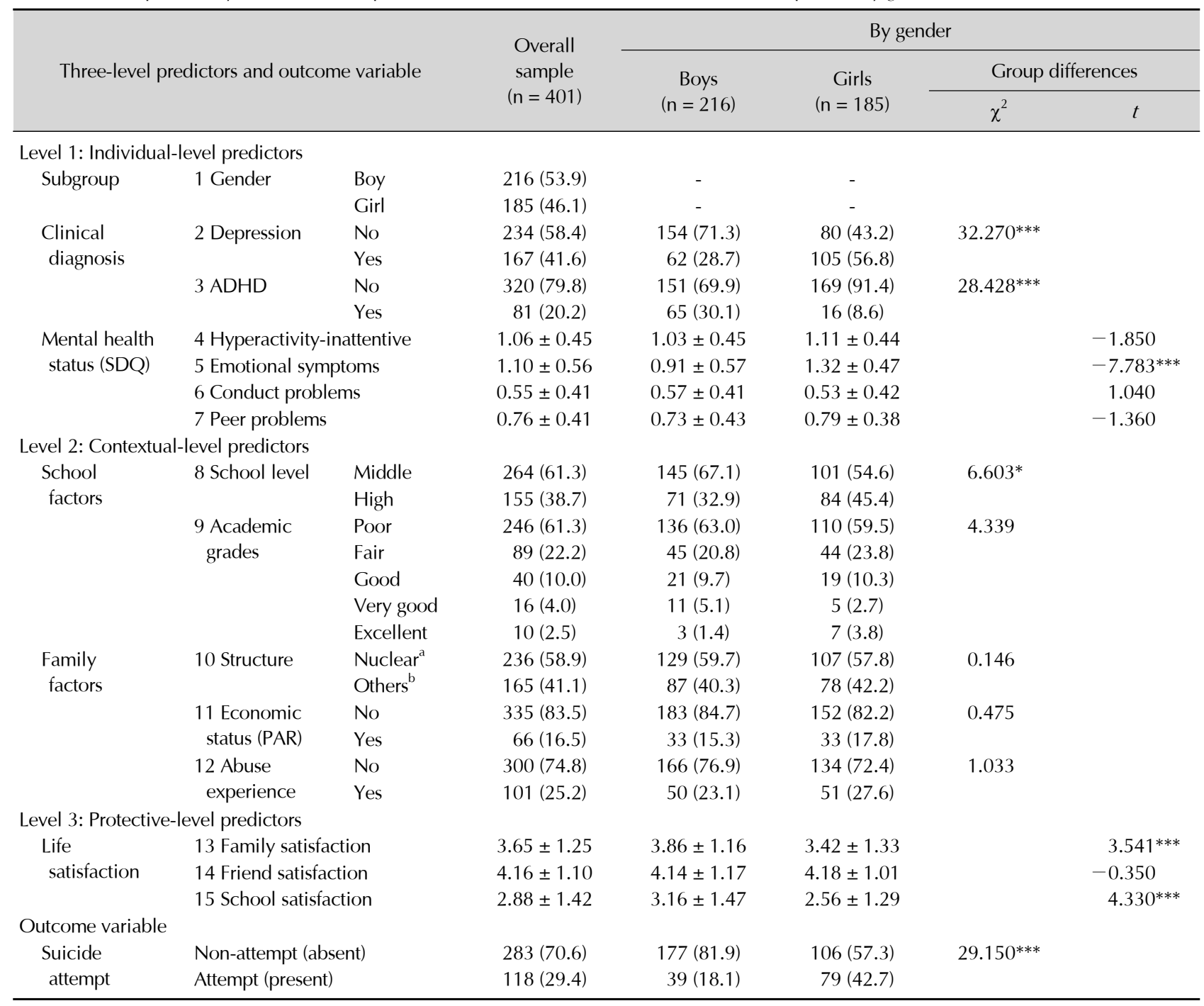

Values are presented as frequency $(\%)$ or mean \pm standard deviation.

ADHD, attention-deficit/hyperactivity disorder; SDQ, Strengths and Difficulties Questionnaire; PAR, public assistance recipients.

${ }^{\mathrm{a}} \mathrm{A}$ family structure consisting of two parents (both father and mother) and their children; ${ }^{b}$ Other family structures (e.g., extended family, single parent' family).

Asterisks indicate statistical significance between genders; ${ }^{*} p<0.05,{ }^{* *} p<0.01,{ }^{* * *} p<0.001$. 
Table 2. Univariate logistic regression analysis of the overall sample

\begin{tabular}{|c|c|c|c|c|c|c|c|}
\hline \multicolumn{2}{|c|}{ Three-level predictors } & B & SE & Wald & $\mathrm{df}$ & Sig. & $\operatorname{Exp}(B)$ \\
\hline \multicolumn{8}{|c|}{ Level 1: Individual-level predictors } \\
\hline Subgroup & 1 Gender* & 1.22 & 0.23 & 27.817 & 1 & 0.000 & 3.38 \\
\hline \multirow{2}{*}{$\begin{array}{l}\text { Clinical } \\
\text { diagnosis }\end{array}$} & 2 Depression* & 0.83 & 0.22 & 13.750 & 1 & 0.000 & 2.29 \\
\hline & 3 ADHD* & -0.94 & 0.33 & 8.314 & 1 & 0.004 & 0.39 \\
\hline \multirow{4}{*}{$\begin{array}{l}\text { Mental health } \\
\text { status }\end{array}$} & 4 Hyper-inattentive* & 0.90 & 0.26 & 12.134 & 1 & 0.000 & 2.46 \\
\hline & 5 Emotional symptoms* & 1.07 & 0.22 & 23.620 & 1 & 0.000 & 2.90 \\
\hline & 6 Conduct problems* & 0.52 & 0.26 & 3.899 & 1 & 0.048 & 1.57 \\
\hline & 7 Peer problems* & 0.81 & 0.27 & 8.879 & 1 & 0.003 & 2.25 \\
\hline \multicolumn{8}{|c|}{ Level 2: Contextual-level predictors } \\
\hline \multirow[t]{2}{*}{ School factors } & 8 School level* & 0.47 & 0.22 & 4.433 & 1 & 0.035 & 1.60 \\
\hline & 9 Academic grades* & 0.24 & 0.11 & 7.124 & 1 & 0.008 & 1.33 \\
\hline \multirow[t]{3}{*}{ Family factors } & 10 Structure (n.s.) & -0.07 & 0.22 & 0.104 & 1 & 0.747 & 0.93 \\
\hline & 11 Economic status (n.s.) & -0.13 & 0.30 & 0.176 & 1 & 0.675 & 0.88 \\
\hline & 12 Abuse exp. (n.s.) & 0.08 & 0.25 & 0.104 & 1 & 0.747 & 1.08 \\
\hline \multicolumn{8}{|c|}{ Level 3: Protective-level predictors } \\
\hline \multirow[t]{3}{*}{ Life satisfaction } & 13 Family* & -0.37 & 0.09 & 16.730 & 1 & 0.000 & 0.69 \\
\hline & 14 Friend (excluded) & $(-0.12)$ & $(0.109)$ & $(1.453)$ & 1 & $(0.228)$ & (0.89) \\
\hline & 15 School* & -0.25 & 0.08 & 9.009 & 1 & 0.003 & 0.78 \\
\hline
\end{tabular}

B, unstandardized beta; $\mathrm{SE}$, standard error; $\mathrm{ADHD}$, attention-deficit/hyperactivity disorder; Hyper-inattentive, hyperactivity-inattentive; n.s., not significant.

Asterisk indicates statistical significance at the 0.001 level; The predictor 14 (friends satisfaction) was excluded due to the multicollinearity with predictor 7 (peer problems).

With respect to level 3, boys $(M=3.86, \mathrm{SD}=1.16)$ were significantly more satisfied with their family than were girls $(M=3.42, \mathrm{SD}=1.33)$. Moreover, boys $(M=3.16, \mathrm{SD}=$ 1.47) also had significantly higher school satisfaction than girls $(M=2.56, \mathrm{SD}=1.29)$.

\section{Suicide Attempt Rate}

The suicide attempt rate of the overall sample was $29.4 \%$ (see Table 1 ). According to gender, $18.1 \%$ of boys and $42.7 \%$ of girls attempted suicide. The $\chi^{2}$ analysis showed that girls attempted suicide significantly more frequently than boys, $\chi^{2}=29.150, p<0.001$.

\section{Correlations between Predictors}

Correlation analysis was conducted to identify multicollinearity among the 15 predictors. Due to the predictors being measured on different types of scales (e.g., nominal vs. interval), Cramer's $\vee$, contingency coefficient, Eta, and Pearson correlation were separately performed. A significant negative correlation (above 0.5) was found between predictor 7 (peer problems) and predictor 14 (friend satisfaction) $(r=-0.61)$, indicating a problem with multicollinearity. To select one of these two predictors (predictors 7 and 14), univariate logistic regression was performed in the following step. No significant effect was found for predictor 14, which was then excluded from the final analysis.

\section{Univariate Logistic Regression}

As shown in Table 2, 11 predictors had a significant association with suicide attempts and were included in the hierarchical logistic regression model for the multilevel analyses.

\section{Multivariate Hierarchical Logistic Regression}

Table 3 provides the multilevel model fit statistics for the three models and Table 4 shows each predictor's predictive capabilities in terms of adolescents' suicide attempts for the overall sample and by gender.

As shown in Table 3, for the overall sample, all three models had statistically significant results at the $0.001 \mathrm{lev}$ el in terms of model fit (Model 1: $\chi^{2}=55.879$; Model 2: $\chi^{2}=$ 62.581; and Model 3: $\left.\chi^{2}=69.069\right)$. With regard to model changes, Model 2 was significantly improved at the 0.05 level $\left(\chi^{2}\right.$ change $=6.702$ ) by adding contextual-level predictors (level 2) to Model 1. Model 3 was also improved at the 0.05 level $\left(\chi^{2 \text { change }}=6.488\right)$ when protective-level predictors (level 3) were added to Model 2. These results imply that all individual, contextual, and protective-level predictors significantly contributed to predicting the over- 
Table 3. Model fit statistics for each model (overall sample and by gender)

\begin{tabular}{|c|c|c|c|c|c|c|c|}
\hline \multicolumn{2}{|c|}{ Samples } & \multirow{2}{*}{$\begin{array}{l}\text { Model } \chi^{2} \\
55.879^{* * *}\end{array}$} & \multirow{2}{*}{$\begin{array}{c}\text { Step } \chi^{2} \\
55.879 * * *\end{array}$} & \multirow{2}{*}{$\begin{array}{r}\text { df } \\
7\end{array}$} & \multirow{2}{*}{$\begin{array}{l}-2 \log \mathrm{L} \\
430.074\end{array}$} & \multirow{2}{*}{$\begin{array}{c}\text { Nagelkerke } \mathrm{R}^{2} \\
0.185\end{array}$} & \multirow{2}{*}{$\begin{array}{c}\text { Overall } \\
\text { correct }(\%)\end{array}$} \\
\hline Overall sample & Model 1 & & & & & & \\
\hline$(\mathrm{n}=401)$ & Model 2 & $62.581^{* * *}$ & $6.702^{*}$ & 9 & 423.372 & 0.206 & 71.8 \\
\hline & Model 3 & $69.069^{* * *}$ & $6.488^{*}$ & 11 & 416.884 & 0.225 & 73.1 \\
\hline \multicolumn{8}{|l|}{ By gender } \\
\hline \multirow{3}{*}{ Boys $(n=216)$} & Model 1 & $25.896^{* * *}$ & $25.896^{* * *}$ & 6 & 178.109 & 0.185 & 81.9 \\
\hline & Model 2 & $31.027^{* * *}$ & 5.131 & 8 & 172.979 & 0.219 & 84.3 \\
\hline & Model 3 & $33.335^{* * *}$ & 2.308 & 10 & 170.671 & 0.234 & 84.3 \\
\hline \multirow[t]{3}{*}{ Girls $(n=185)$} & Model 1 & 7.368 & 7.368 & 6 & 245.142 & 0.052 & 60.5 \\
\hline & Model 2 & 13.411 & $6.043^{*}$ & 8 & 239.099 & 0.094 & 61.6 \\
\hline & Model 3 & $20.474 *$ & $7.064^{*}$ & 10 & 232.035 & 0.141 & 63.8 \\
\hline
\end{tabular}

Model 1: individual-level predictors; Model 2: individual and contextual-level predictors; Model 3: individual-, contextual-, and protective level predictors.

Asterisks indicate statistical significance; ${ }^{*} p<0.05,{ }^{* *} p<0.01,{ }^{* * *} p<0.001$.

Table 4. Multilevel logistic regression analysis of the overall sample and by gender

\begin{tabular}{|c|c|c|c|c|c|c|c|c|c|c|c|c|}
\hline \multirow{3}{*}{ Predictors } & \multirow{2}{*}{\multicolumn{4}{|c|}{$\begin{array}{l}\text { Overall sample } \\
\qquad(\mathrm{n}=401)\end{array}$}} & \multicolumn{8}{|c|}{ By gender } \\
\hline & & & & & \multicolumn{4}{|c|}{ Boys $(n=216)$} & \multicolumn{4}{|c|}{ Girls $(n=185)$} \\
\hline & B & OR & Lower & Upper & B & OR & Lower & Upper & B & OR & Lower & Upper \\
\hline \multicolumn{13}{|c|}{ Level 1: Individual-level predictors } \\
\hline 1 Gender & $0.92^{\mathrm{a}, * * *}$ & $2.51^{\mathrm{a}}$ & $1.50^{\mathrm{a}}$ & $4.19^{\mathrm{a}}$ & & - & - & - & & - & - & \\
\hline 2 Depression & 0.38 & 1.47 & 0.87 & 2.49 & $0.97^{\mathrm{a}, *}$ & $2.65^{\mathrm{a}}$ & $1.09^{\mathrm{a}}$ & $6.42^{\mathrm{a}}$ & 0.01 & 1.00 & 0.51 & 1.98 \\
\hline $3 \mathrm{ADHD}$ & -0.35 & 0.71 & 0.36 & 1.53 & -0.23 & 0.80 & 0.25 & 2.50 & -0.10 & 0.91 & 0.27 & 3.00 \\
\hline $\begin{array}{l}4 \text { Hyperactivity- } \\
\text { inattentive }\end{array}$ & 0.57 & 1.77 & 0.95 & 3.32 & 0.38 & 1.46 & 0.53 & 4.03 & 0.84 & 2.32 & 0.98 & 5.48 \\
\hline 5 Emotional symptoms & 0.19 & 1.21 & 0.69 & 2.11 & 0.21 & 1.24 & 0.53 & 2.92 & 0.04 & 1.04 & 0.47 & 2.27 \\
\hline 6 Conduct problems & 0.47 & 1.61 & 0.84 & 3.07 & $1.34^{\mathrm{a}, * *}$ & $3.85^{\mathrm{a}}$ & $1.39^{\mathrm{a}}$ & $10.53^{\mathrm{a}}$ & -0.26 & 0.77 & 0.32 & 1.85 \\
\hline 7 Peer problems & 0.46 & 1.59 & 0.83 & 3.06 & 0.22 & 1.25 & 0.45 & 3.47 & 0.80 & 2.23 & 0.88 & 5.65 \\
\hline \multicolumn{13}{|c|}{ Level 2: Contextual-level predictors } \\
\hline 8 School level & 0.14 & 1.15 & 0.70 & 1.88 & 0.72 & 2.06 & 0.88 & 4.82 & -0.25 & 0.78 & 0.41 & 1.48 \\
\hline 9 Academic grades & $0.33^{\mathrm{a}, *}$ & $1.38^{\mathrm{a}}$ & $1.08^{\mathrm{a}}$ & $1.77^{\mathrm{a}}$ & 0.32 & 1.38 & 0.91 & 2.09 & $0.34^{\mathrm{a}, *}$ & $1.40^{\mathrm{a}}$ & $1.00^{\mathrm{a}}$ & $1.96^{\mathrm{a}}$ \\
\hline \multicolumn{13}{|c|}{ Level 3: Protective-level predictors } \\
\hline 13 Family satisfaction & $-0.25^{\mathrm{a}, *}$ & $0.78^{\mathrm{a}}$ & $0.63^{\mathrm{a}}$ & $0.96^{\mathrm{a}}$ & -0.16 & 0.85 & 0.58 & 1.25 & $-0.35^{\mathrm{a}, *}$ & $0.71^{\mathrm{a}}$ & $0.54^{\mathrm{a}}$ & $0.92^{\mathrm{a}}$ \\
\hline 15 School satisfaction & -0.01 & 0.99 & 0.80 & 1.21 & -0.15 & 0.86 & 0.63 & 1.18 & 0.17 & 1.18 & 0.88 & 1.98 \\
\hline
\end{tabular}

Eleven predictors were selected based on Table 2.

ADHD, attention-deficit/hyperactivity disorder; $B$, unstandardized coefficients; odds ratio $(O R)=\operatorname{Exp}(B)$.

${ }^{\text {a }}$ Statistical significance. ${ }^{*} p<0.05,{ }^{* *} p<0.01,{ }^{* * *} p<0.001$.

all sample's suicide attempts.

All three models for boys were statistically significant at the 0.001 level (Model 1: $\chi^{2}=25.896$; Model 2: $\chi^{2}=$ 31.027; and Model 3: $\left.\chi^{2}=33.335\right)$. In terms of model changes, neither Model $2\left(\chi^{2 \text { change }}=5.131\right)$ nor Model 3 $\left(\chi^{2 \text { change }}=2.308\right)$ significantly improved the previous models, when contextual and protective-level predictors were added to the logistic regression equation. These results imply that individual-level predictors have the most significant contribution in predicting boys' suicide attempts, compared to contextual- and protective-level predictors.
In contrast to the findings for boys, only Model 3 for girls showed small but significant model fit $\left(\chi^{2}=20.474\right)$. With respect to model changes, Model 2 was significantly improved by adding contextual-level predictors to Model $1\left(\chi^{2 \text { change }}=6.043\right)$. Also, Model 3 was significantly improved when protective-level predictors were added to Model $2\left(\chi^{2 \text { change }}=7.064\right)$. These results imply that protective-level predictors contribute the most to the prediction of suicide attempts by girls, followed by contextual-level predictors.

As for each predictor's predictive capabilities (see Table 
$4)$, gender $(B=0.92)$ was significantly associated with the overall sample's suicide attempts, such that girls were 2.51 times more likely to attempt suicide (95\% confidence interval $[\mathrm{Cl}]: 1.50-4.19)$ than boys.

Significant predictors related to boys' suicide attempts were depression $(B=0.97)$ and conduct problems $(B=$ 1.34). Boys with depression were about 2.65 times more likely to attempt suicide $(95 \% \mathrm{Cl}$ : $1.09-6.42)$ than those without depression. Also, boys with higher conduct problems were 3.85 times more likely to attempt suicide (95\% Cl: $1.39-10.53)$ than those with lower conduct difficulties. In contrast to the findings for boys, family satisfaction ( $B=$ $-0.35)$ and academic grades $(B=0.34)$ were significantly influential predictors associated with girls' suicide attempts. Girls with lower family satisfaction were 0.71 times more likely to attempt suicide (95\% Cl: 0.54-0.92) than those with higher family satisfaction. Also, girls with higher academic grades were 1.40 times more likely to attempt suicide (95\% Cl: $1.00-1.96)$ than those with lower grades.

\section{Ethics Approval and Consent to Participate}

This study was approved by the Institutional Review Board of Hallym University Sacred Heart Hospital (HALLYM 2018-08-002-001). All procedures performed in studies involving human participants were in accordance with the ethical standards of the institutional and/or national research committee and with the 1964 Helsinki declaration and its later amendments or comparable ethical standards.

\section{DISCUSSION}

The purpose of this study was to investigate how individual-, contextual-, and protective-level predictors affected at-risk non-referred adolescents' suicide attempts and to compare the results by gender. This study's sample showed a higher suicide attempt rate than community samples, displayed high levels of psychosocial differences and showed different risk and protective factors depending on gender.

The suicide attempt rate of the overall sample was $29.4 \%$, which was lower than that of clinically depressed adolescent samples (47.2\%) [9], but considerably higher than that of community samples (2.6\%) [8]. The difference in suicide attempt rates can be interpreted as a re- flection of the unique characteristics of the study samples. Similar to clinically depressed adolescent samples, this study samples were vulnerable and exposed to risk. However, they were found and received medical expenses compensation through the Professional School Visits Project and were able to undergo psychiatric treatment. Since psychiatric treatment was effective in reducing the suicidal behavior of clinical samples $[46,47]$, it is expected to be effective in this study sample, which has similar or even more severe characteristics. Therefore, implementing a policy to increase the accessibility of professional intervention in these samples could contribute to preventing suicide.

Significant gender differences in suicide attempt rates (girls: $42.7 \%$, boys: $18.1 \%$ ) were also demonstrated. The suicide attempt rate for girls was higher than that for boys for both community (girls: 3.2\%, boys: 2.0\%) [8] and clinically depressed samples (girls: $54.9 \%$, boys: $31.4 \%$ ) [9]. These results are consistent with previous studies that showed adolescent girls' suicide attempts are 2 to 3 times higher than those of adolescent boys $[10,48]$. The rate of suicide attempts increases as puberty develops [49]. From a developmental perspective, girls start puberty sooner than boys [50]. This may contribute to the higher rate of girls' suicide attempts $[1,49,50]$.

Previous studies have reported that family-related factors have a significant impact in predicting adolescents' suicide attempts $[1,12,15,16,29,35]$; the results of this study did not prove otherwise, which could be interpreted as follows. First, the concept of vulnerable family environment in this study sample should be considered. In 2017, the divorce rate in Korea was $2.1 \%$, and the rate of family abuse was $2.2 \%$ [8]. For this study's sample, however, $41.1 \%$ of adolescents belonged to other family types (e.g., divorced family) and $25.3 \%$ of adolescents experienced family abuse, indicating evidence of vulnerability in terms of poor family environment. Thus, unlike in community samples, family-related factors were not significant influential risk factors for attempting suicide in this already vulnerable at-risk non-referred sample. Second, family economic difficulties had a less significant contribution to adolescents' suicide attempts, compared to the characteristics of adult suicides [30]. This can be explained such that family economic status is often not a major consideration for adolescents. That is, they are either unaware of the economic condition of their family or recognize the 
family's economic status but tend to be less concerned (compared to their concerns about peers and school).

Gender was an influential factor in predicting suicide attempts of the overall sample, with the girls attempting suicide significantly more frequently than boys. These findings are consistent with previous studies that showed girls are more vulnerable to suicidal behaviors than boys $[10,48,51]$. For boys, both depression and emotional problems showed up as significant risk factors in the univariate analysis. In the multilevel analysis, however, only depression was significant, although these two variables are expected to be highly correlated. This can be interpreted to mean that either depression is a more influential factor in suicide attempts than a broad range of emotional problems or that objective clinical evaluation by a professional may be more sensitive for assessment of suicide risk than a self-assessment of emotional problems. In addition, in multilevel analysis, individual-level predictors (depression and conduct problems) proved to have the most significant contribution in predicting boys' suicide attempts. That means that these vulnerable boys with higher depression or more conduct problems are more likely to attempt suicide than those with lower depression or fewer conduct problems, and therefore, professionals need to be more sensitive to this group's suicidal risk. Depression is a well-known risk factor in predicting suicide attempts in boy adolescents [52], and the impact of conduct disorder on suicidal behavior in males is higher than in females $[28,53,54]$. Young males may be less predisposed to help-seeking behaviors in an attempt to exhibit masculine behaviors [55] or a male tendency to adopt avoidance strategies [56], and adolescents with behavioral problems have difficulty socializing with others and form superficial relationships [22]. These factors may contribute to making it more difficult for them to cope with emotional and behavioral problems and easily lead to suicidal behavior.

For girls, on the other hand, protective-level predictors (family satisfaction) contributed the most to the prediction of suicide attempts, followed by contextual-level predictors (academic grades). That is, girls with less family satisfaction and those with higher academic grades were more likely to attempt suicide than those with more family satisfaction and with lower academic grades. This finding implies that family satisfaction played a significant role as a protective factor to reduce the likelihood of girls' at- tempting suicide [35,37]. In addition, whereas previous studies showed that low academic grades significantly affected adolescents' suicidal behaviors [10,57], this study found that academic grades had a significant impact on girls, especially when their grades were higher. This can be explained in terms of relative deprivation. Although their academic grades were high, it might have been difficult to receive psychological and financial support from their parents; therefore, as previous studies mentioned that the frustration they experienced is estimated to be greater than that of adolescents in community samples $[58,59]$. Furthermore, considering our results, in the case of girls with high academic achievement who have grown up with a low socioeconomic status and poor family relationships, it may be necessary to provide an appropriate community care system that can give psychological and social welfare support outside the home for reducing suicide risk. This system could help girls overcome their relative deprivation and adjust psychologically as well as provide opportunities for them to explore their own strength. Lastly, regarding girls' depression, it should be noted that the samples in this study are not community samples, has not set up in control groups, and are all mental high-risk samples. If the factors affecting girls' suicidal behaviors had been analyzed in this sample through a comparison with normal control groups, the relationship with depression in girls may have been greater, as has been previously shown $[1,19,20]$. However, the factors affecting the suicide attempts of this sample may differ from those in previous studies because the girls in this study belong to highly vulnerable at-risk mental health groups.

Several limitations must be addressed in this study. First, the research samples were adolescents (aged 1318 years). Other age groups, such as younger children (aged 10-12 years), were not included in this study. Considering the tendency that suicidal behaviors gradually lower with age [60-62], further studies on older children should be carried out in the future. Second, there was no information about the severity of suicide attempts (e.g., frequency, methods, situation at the time of suicide attempt). Depending on the severity, the factors involved are expected to vary. Therefore, further studies are suggested to identify non-suicide attempts, suicide attempts, and repeated suicide attempts based on their severity, and then compare among groups [52]. Third, this study analyzed data derived from the National School Mental 
Health Project. Thus, there are limitations such that diagnoses (e.g., depression, ADHD) were not made through structured interviews and validated instruments for specific psychiatric symptoms. Clinical psychiatric evaluations should be used for more accurate diagnoses in the future [63].

Despite these limitations, the implications of this study should be acknowledged. First, given that most studies of adolescent suicide were carried out either with community or clinical samples, this study investigated at-risk noneferred adolescents and compared by gender. That is, this study is an essential step in understanding the unique characteristics of these vulnerable samples that have not yet been addressed in mental health policies. Improving medical accessibility will be the first step in establishing effective suicide prevention policies for the at-risk non-referred adolescent samples. In addition, whereas previous studies analyzed various influential factors at one level, this study applied multi-level analysis to more specifically investigate at-risk non-referred adolescents' suicide attempts. Thus, the findings of this study highlight the need to examine vulnerable boys' and girls' suicidal behaviors in a hierarchical structure, which in turn will inform policies that can help these adolescents overcome their difficulties and become healthy members of Korean society.

\section{Acknowledgments}

This work was supported by the Ministry of Education of the Republic of Korea and the National Research Foundation of Korea (NRF-2015S1A5B8A02061201).

\section{Conflicts of Interest}

No potential conflict of interest relevant to this article was reported.

\section{Author Contributions}

Conceptualization: Hyun Ju Hong, Yumi Lee, Dayoung Lee. Data acquisition: Yumi Lee. Formal analysis: Yumi Lee. Funding: Hyun Ju Hong. Supervision: Hyun Ju Hong, Writing—original draft: Yumi Lee. Writing —review \& editing: Hyun Ju Hong, Dayoung Lee, Yumi Lee.

\section{ORCID}

Yumi Lee

Dayoung Lee

Hyun Ju Hong https://orcid.org/0000-0002-0584-3643

https://orcid.org/0000-0002-4399-4231

https://orcid.org/0000-0002-6348-9996

\section{REFERENCES}

1. Bridge JA, Goldstein TR, Brent DA. Adolescent suicide and suicidal behavior. J Child Psychol Psychiatry 2006;47:372394.

2. ten Have M, de Graaf R, van Dorsselaer S, Verdurmen J, van't Land H, Vollebergh W, et al. Incidence and course of suicidal ideation and suicide attempts in the general population. Can J Psychiatry 2009;54:824-833.

3. Flouri $\mathrm{E}$, Buchanan A. The protective role of parental involvement in adolescent suicide. Crisis 2002;23:17-22.

4. Fotti SA, Katz LY, Afifi TO, Cox BJ. The associations between peer and parental relationships and suicidal behaviours in early adolescents. Can J Psychiatry 2006;51:698-703.

5. Kidd S, Henrich CC, Brookmeyer KA, Davidson L, King RA, Shahar G. The social context of adolescent suicide attempts: interactive effects of parent, peer, and school social relations. Suicide Life Threat Behav 2006;36:386-395.

6. Suominen K, Isometsä E, Suokas J, Haukka J, Achte K, Lönnqvist J. Completed suicide after a suicide attempt: a 37-year follow-up study. Am J Psychiatry 2004;161:562-563.

7. Wang AG, Mortensen G. Core features of repeated suicidal behaviour: a long-term follow-up after suicide attempts in a low-suicide-incidence population. Soc Psychiatry Psychiatr Epidemiol 2006;41:103-107.

8. Korean Statistical Information Service. National adolescents suicide attempt rate in 2017 [Internet]. Daejeon: Statistics Korea; 2017 [cited at $2018 \mathrm{Jul}$ 2]. Available from: http://kosis. kr/statHtml/statHtml.do?orgld=117\&tbl/d=DT_117_12_ $\mathrm{Y}$ $071 \& \mathrm{v} w_{-} c d=\& l i s t \_i d=\& s c r l d=\& s e q N o=\& l a n g \_$mode $=k o \&$ obj_var_id=\&itm_id=\&conn_path $=K 1$.

9. Kwon A, Song J, Yook KH, Jon DI, Jung MH, Hong $\mathrm{N}$, et al. Predictors of suicide attempts in clinically depressed Korean adolescents. Clin Psychopharmacol Neurosci 2016;14:383387.

10. Boeninger DK, Masyn KE, Feldman BJ, Conger RD. Sex differences in developmental trends of suicide ideation, plans, and attempts among European American adolescents. Suicide Life Threat Behav 2010;40:451-464.

11. Hong NM, Chung YS. Path analysis on adolescent's suicidal ideation -a comparison of adolescent suicide attempters and non-attempters-. Journal of the Korean Society of Child Welfare. 2012; (40):255-283.

12. Hawton K, Saunders KE, O'Connor RC. Self-harm and suicide in adolescents. Lancet 2012,379:2373-2382.

13. Choi KH, Wang SM, Yeon B, Suh SY, Oh Y, Lee HK, et al. Risk and protective factors predicting multiple suicide attempts. Psychiatry Res 2013;210:957-961.

14. Kuo WH, Gallo JJ, Eaton WW. Hopelessness, depression, substance disorder, and suicidality--a 13-year community-based study. Soc Psychiatry Psychiatr Epidemiol 2004;39:497-501.

15. Evans E, Hawton K, Rodham K. Factors associated with suicidal phenomena in adolescents: a systematic review of population-based studies. Clin Psychol Rev 2004;24:957-979. 
16. Consoli A, Peyre H, Speranza M, Hassler C, Falissard B, Touchette E, et al. Suicidal behaviors in depressed adolescents: role of perceived relationships in the family. Child Adolesc Psychiatry Ment Health 2013;7:8.

17. Jung S, Lee D, Park S, Hong HJ. Subtypes of suicidal ideation in Korean adolescents: a multilevel latent profile analysis. Aust N ZJ Psychiatry 2019;53:158-167.

18. Lee D, Jung S, Park S, Hong HJ. The impact of psychological problems and adverse life events on suicidal ideation among adolescents using nationwide data of a school-based mental health screening test in Korea. Eur Child Adolesc Psychiatry 2018;27:1361-1372.

19. Allison S, Roeger L, Martin G, Keeves J. Gender differences in the relationship between depression and suicidal ideation in young adolescents. Aust N Z J Psychiatry 2001;35:498-503.

20. Lewinsohn PM, Rohde P, Seeley JR, Baldwin CL. Gender differences in suicide attempts from adolescence to young adulthood. I Am Acad Child Adolesc Psychiatry 2001;40: 427-434.

21. Impey M, Heun R. Completed suicide, ideation and attempt in attention deficit hyperactivity disorder. Acta Psychiatr Scand 2012; 125:93-102.

22. Galéra C, Bouvard MP, Encrenaz G, Messiah A, Fombonne E. Hyperactivity-inattention symptoms in childhood and suicidal behaviors in adolescence: the Youth Gazel Cohort. Acta Psychiatr Scand 2008; 118:480-489.

23. Chronis-Tuscano A, Molina BS, Pelham WE, Applegate B, Dahlke A, Overmyer M, et al. Very early predictors of adolescent depression and suicide attempts in children with attention-deficit/hyperactivity disorder. Arch Gen Psychiatry 2010; 67:1044-1051.

24. Groholt B, Ekeberg O. Prognosis after adolescent suicide attempt: mental health, psychiatric treatment, and suicide attempts in a nine-year follow-up study. Suicide Life Threat Behav 2009;39:125-136.

25. King RA, Schwab-Stone M, Flisher AJ, Greenwald S, Kramer RA, Goodman SH, et al. Psychosocial and risk behavior correlates of youth suicide attempts and suicidal ideation. I Am Acad Child Adolesc Psychiatry 2001;40:837-846.

26. Resch F, Parzer P, Brunner R; BELLA study group. Self-mutilation and suicidal behaviour in children and adolescents: prevalence and psychosocial correlates: results of the BELLA study. Eur Child Adolesc Psychiatry 2008;17 Suppl 1:92-98.

27. Manor I, Gutnik I, Ben-Dor DH, Apter A, Sever J, Tyano S, et al. Possible association between attention deficit hyperactivity disorder and attempted suicide in adolescents - a pilot study. Eur Psychiatry 2010;25:146-150.

28. Brent DA, Baugher M, Bridge J, Chen T, Chiappetta L. Ageand sex-related risk factors for adolescent suicide. J Am Acad Child Adolesc Psychiatry 1999;38:1497-1505.

29. Prinstein MJ, Boergers J, Spirito A, Little TD, Grapentine WL. Peer functioning, family dysfunction, and psychological symptoms in a risk factor model for adolescent inpatients' sui- cidal ideation severity. J Clin Child Psychol 2000;29:392-405.

30. Yi S, Yi Y, Jung HS. Factors on the suicidal attempt by gender of middle and high school student. J Korean Acad Nurs 2011; 41:652-662.

31. Cho SJ, Jeon HJ, Kim JK, Suh TW, Kim SU, Hahm BJ, et al. Prevalence of suicide behaviors(suicidal ideation and suicide attempt) and risk factors of suicide attempts in junior and high school adolescents. J Korean Neuropsychiatr Assoc 2002;41: 1142-1155.

32. Brent D. What family studies teach us about suicidal behavior: implications for research, treatment, and prevention. Eur Psychiatry 2010;25:260-263.

33. Dieserud G, Gerhardsen RM, Van den Weghe H, Corbett K. Adolescent suicide attempts in Bærum, Norway, 1984-2006. Crisis 2010;31:255-264.

34. Xing XY, Tao FB, Wan YH, Xing C, Qi XY, Hao JH, et al. Family factors associated with suicide attempts among Chinese adolescent students: a national cross-sectional survey. J Adolesc Health 2010:46:592-599.

35. Sharaf AY, Thompson EA, Walsh E. Protective effects of selfesteem and family support on suicide risk behaviors among at-risk adolescents. J Child Adolesc Psychiatr Nurs 2009;22: 160-168.

36. Gilman R, Huebner S. A review of life satisfaction research with children and adolescents. School Psychology Quarterly. 2003;18:192-205.

37. Suldo SM, Huebner ES. The role of life satisfaction in the relationship between authoritative parenting dimensions and adolescent problem behavior. Soc Indic Res 2004;66:165195.

38. Neto F, Barros J. Satisfaction with life among adolescents from Portuguese immigrant families in Switzerland. Swiss J Psychol 2007;66:215-223.

39. Noh H, Lee JI, Jun GH. Gender differences in risk and protective factors that predict suicide attempts among elementary and middle school students. I Adolesc Welf 2012;14: 335-363.

40. Grøholt B, Ekeberg O, Wichstrøm L, Haldorsen T. Young suicide attempters: a comparison between a clinical and an epidemiological sample. J Am Acad Child Adolesc Psychiatry 2000;39:868-875.

41. Korea Centers for Disease Control and Prevention. The 13th Korea Youth Risk Behavior Web-based Survey, 2017 [Internet]. Sejong: Ministry of Health and Welfare; 2017 [cited at 2018 Jul]. Available from: https://www.cdc.go.kr/yus/home.jsp.

42. Goodman R. The strengths and difficulties questionnaire: a research note. J Child Psychol Psychiatry 1997;38:581-586.

43. Ahn JS, Jun SK, Han JK, Noh KS, Goodman R. The development of a Korean Version of the Strengths and Difficulties Questionnaire. J Korean Neuropsychiatr Assoc 2003;42:141147.

44. Huebner ES. Preliminary development and validation of a multidimensional life satisfaction scale for children. 
Psychological Assessment 1994;6:149-158.

45. Lee JM. Validation of the Korean Version of Multidimensional Students`Life Satisfaction Scale(K-MSLSS) for adolescents. Korean I Dev Psychol 2011;24:115-133.

46. American Academy of Child and Adolescent Psychiatry. Practice parameter for the assessment and treatment of children and adolescents with suicidal behavior. I Am Acad Child Adolesc Psychiatry 2001;40(7 Suppl):24S-51S.

47. Asarnow JR, Porta G, Spirito A, Emslie G, Clarke G, Wagner $\mathrm{KD}$, et al. Suicide attempts and nonsuicidal self-injury in the treatment of resistant depression in adolescents: findings from the TORDIA study. J Am Acad Child Adolesc Psychiatry 2011; 50:772-781.

48. Watt TT, Sharp SF. Gender differences in strains associated with suicidal behavior among adolescents. I Youth Adolesc 2001;30:333-348.

49. Fergusson DM, Woodward LJ, Horwood LJ. Risk factors and life processes associated with the onset of suicidal behaviour during adolescence and early adulthood. Psychol Med 2000; 30:23-39.

50. Wichstrøm L. Predictors of adolescent suicide attempts: a nationally representative longitudinal study of Norwegian adolescents. J Am Acad Child Adolesc Psychiatry 2000;39: 603-610.

51. Kang EH, Hyun MK, Choi SM, Kim JM, Kim GM, Woo JM. Twelve-month prevalence and predictors of self-reported suicidal ideation and suicide attempt among Korean adolescents in a web-based nationwide survey. Aust N Z J Psychiatry 2015:49:47-53.

52. Andover MS, Morris BW, Wren A, Bruzzese ME. The Co-occurrence of non-suicidal self-injury and attempted suicide among adolescents: distinguishing risk factors and psychosocial correlates. Child Adolesc Psychiatry Ment Health 2012;6:11.

53. Merikangas KR, He JP, Burstein M, Swanson SA, Avenevoli S,
Cui L, et al. Lifetime prevalence of mental disorders in US adolescents: results from the National Comorbidity Study-Adolescent Supplement (NCS-A). I Am Acad Child AdolesC Psychiatry 2010;49:980-989.

54. Shaffer D, Gould MS, Fisher P, Trautman P, Moreau D, Kleinman $\mathrm{M}$, et al. Psychiatric diagnosis in child and adolescent suicide. Arch Gen Psychiatry 1996;53:339-348.

55. Rhodes AE, Boyle MH, Bridge JA, Sinyor M, Links PS, Tonmyr $\mathrm{L}$, et al. Antecedents and sex/gender differences in youth suicidal behavior. World I Psychiatry 2014;4:120-132.

56. Gould MS, Velting D, Kleinman M, Lucas C, Thomas JG, Chung M. Teenagers' attitudes about coping strategies and help-seeking behavior for suicidality. I Am Acad Child Adolesc Psychiatry 2004;43:1124-1133.

57. Nam YO. The factors affecting adolescents`suicide ideation and suicide attempts. Korean J Youth Stud 2013;20:283-304.

58. Dashiff C, DiMicco W, Myers B, Sheppard K. Poverty and adolescent mental health. J Child Adolesc Psychiatr Nurs 2009;22:23-32.

59. Bradley RH, Corwyn RF. Socioeconomic status and child development. Annu Rev Psychol 2002;53:371-399.

60. Sheftall AH, Asti L, Horowitz LM, Felts A, Fontanella CA, Campo JV, et al. Suicide in elementary school-aged children and early adolescents. Pediatrics 2016;138:e20160436.

61. Soole R, Kõlves K, De Leo D. Suicide in children: a systematic review. Arch Suicide Res 2015;19:285-304.

62. Hong M, Cho HN, Kim AR, Hong HJ, Kweon YS. Suicidal deaths in elementary school students in Korea. Child Adolesc Psychiatry Ment Health 2017;11:53.

63. Kweon K, Kim HW. Effectiveness and safety of bupropion in children and adolescents with depressive disorders: a retrospective chart review. Clin Psychopharmacol Neurosci 2019;17:537-541. 